\title{
Sphingosine-1-phosphate links glycosphingolipid metabolism to neurodegeneration via a calpain-mediated mechanism
}

\author{
N Hagen ${ }^{1}$, M Hans $^{2}$, D Hartmann ${ }^{3}$, D Swandulla ${ }^{2}$ and G van Echten-Deckert ${ }^{\star, 1}$
}

We have recently reported that the bioactive lipid sphingosine-1-phosphate (S1P), usually signaling proliferation and anti-apoptosis induces neuronal death when generated by sphingosine-kinase2 and when accumulation due to S1P-lyase deficiency occurs. In the present study, we identify the signaling cascade involved in the neurotoxic effect of sphingoid-base phosphates. We demonstrate that the calcium-dependent cysteine protease calpain mediates neurotoxicity by induction of the endoplasmic reticulum stress-specific caspase cascade and activation of cyclin-dependent kinase5 (CDK5). The latter is involved in an abortive reactivation of the cell cycle and also enhances tau phosphorylation. Neuroanatomical studies in the cerebellum document for the first time that indeed neurons with abundant S1P-lyase expression are those, which degenerate first in S1P-lyase-deficient mice. We therefore propose that an impaired metabolism of glycosphingolipids, which are prevalent in the central nervous system, might be linked via S1P, their common catabolic intermediate, to neuronal death.

Cell Death and Differentiation (2011) 18, 1356-1365; doi:10.1038/cdd.2011.7; published online 18 February 2011

Gangliosides, a class of sialic acid containing complex glycosphingolipids are characteristic components of neuronal cells. Neuronal ganglioside profiles vary in different regions of the brain and characteristically change during ontogenesis. ${ }^{1}$ The possible physiological role of these complex molecules for neuronal function and neurodegeneration has been extensively studied. ${ }^{2}$

Reports on elevated expression and activity of enzymes involved in sphingolipid degradation in brain samples of patients suffering from Alzheimer's disease also suggest that less complex metabolic intermediates of these abundant brain lipids might contribute to neurodegeneration. ${ }^{3}$ Among these, ceramide, the central metabolic intermediate and sphingosine-1-phosphate (S1P), the common degradation product of all glycosphingolipids (Figure 1) appear to be of specific interest given their diverse biological functions. ${ }^{4}$ In most cell types S1P and its metabolic precursor ceramide exert antagonistic effects on cell survival. Owing to its tissue protective properties S1P turned out to be primarily a survival signal, whereas ceramide was shown to mediate cellular stress response. ${ }^{4}$

Note that phosphorylation of sphingosine is catalyzed by sphingosine-kinase (SK) of which two distinct isoforms, SK1 and SK2, have been cloned and characterized. ${ }^{5,6}$ Degradation of S1P occurs either via reversible dephosphorylation to sphingosine or via irreversible cleavage by the endoplasmic reticulum (ER) resident S1P-lyase ${ }^{1}$ (Figure 1), suggesting a tight regulation and maintenance of low cellular levels of this bioactive molecule.
S1P exerts its functions either as a ligand for a family of five specific G-protein coupled receptors $\left(\mathrm{S}_{1} \mathrm{P}_{1-5}\right)$ or as an intracellular second messenger. ${ }^{7}$ In contrast to the wellcharacterized receptor-mediated effects of S1P, much less is known about its intracellular actions. One of the intracellular effects of S1P is its involvement in calcium homeostasis. ${ }^{8,9}$ The complex biological effects of S1P are cell type and differentiation specific. Thus, S1P induces proliferation in neuronal progenitor cells ${ }^{10}$ but apoptosis in hippocampal neurons. ${ }^{11}$ We have recently shown that accumulation of S1P in S1P-lyase-deficient neurons induces apoptosis as well. ${ }^{12}$ This neurotoxic effect was independent of S1P receptors but involved dephosphorylation to sphingosine and rephosphorylation catalyzed by SK2. ${ }^{12}$ A similar effect was observed with the synthetic sphingosine analog cis-4-methylsphingosine (cimes). ${ }^{13}$ Cimes is taken up by the cells and mainly phosphorylated by SK2 to form cis-4-methylsphingosine-phosphate (cimesP). ${ }^{12}$ This semi-synthetic S1P analog turned out to be metabolically stable, thus accumulating inside most cell types investigated so far. ${ }^{12-15}$ Like S1P, cimesP stimulated proliferation of quiescent Swiss 3T3 fibroblasts. ${ }^{15}$

S1P generated in the ER membrane has been shown to activate release of calcium from inositol 1,4,5-trisphosphatesensitive calcium pools. ${ }^{8}$ The neurotoxic effect of S1P and cimesP generated by SK2 in ER membranes ${ }^{12}$ might, therefore, be associated with the disruption of calcium homeostasis.

This possibility is supported by experimental evidence indicating that the deregulation of the cysteine protease

${ }^{1}$ LIMES Institute Membrane Biology and Lipid Biochemistry, University of Bonn, Bonn 53121, Germany; ${ }^{2}$ Institute of Physiology, University of Bonn, Bonn 53115, Germany and ${ }^{3}$ Department of Anatomy, Division of Neuroanatomy, University of Bonn, Bonn 53115, Germany

${ }^{*}$ Corresponding author: G van Echten-Deckert, LIMES Institute Membrane Biology and Lipid Biochemistry, University of Bonn, Bonn 53121, Germany.

Tel: + 4922873 2703; Fax: + 4928873 4845; E-mail: g.echten.deckert@uni-bonn.de

Keywords: Sphingosine-1-phosphate; cis-4-methylsphingosine; neurodegeneration; calpain; apoptosis; $\mathrm{Ca}^{2+}{ }_{-}$-release

Abbreviations: AD, Alzheimer's disease; CCCP, carbonyl-cyanide m-chlorophenyl hydrazone; CDK5, cyclin-dependent kinase5; cimes, cis-4-methylsphingosine; cimesP, cis-4-methylsphingosine-phosphate; ER, endoplasmic reticulum; SK, sphingosine-kinase; S1P, sphingosine-1-phosphate; Rb, retinoblastoma protein

Received 16.7.10; revised 16.12.10; accepted 03.1.11; Edited by M Deshmukh; published online 18.2.11 


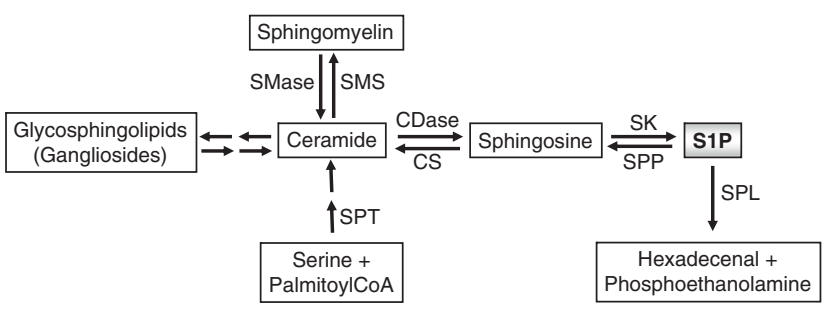

Figure 1 Scheme of sphingolipid metabolism. Ceramide is formed either de novo starting from serine and palmitoylCoA or by hydrolysis of sphingomyelin or glycosphingolipids including gangliosides. In addition, its degradation product sphingosine can be recycled back to ceramide by ceramide synthase (CS). It is degraded by ceramidases (CDases) to yield sphingosine, which in turn is phosphorylated by sphingosine-kinases (SK) to generate sphingosine-1-phosphate (S1P). The latter is either cleaved by S1P-lyase (SPL) into hexadecenal and phosphoethanolamine or dephosphorylated back to sphingosine by S1P. phosphatases (SPP). SMS, sphingomyelin synthase; SMase, sphingomyelinase; SPT, serine palmitoyltransferase.

calpain is a key cytotoxic event in a variety of neurodegenerative processes. ${ }^{16}$ Calpain activity triggered by elevated intracellular calcium levels is often associated with activation of cyclin-dependent kinase 5 (CDK5). ${ }^{16}$ Interestingly, several brain pathologies with neuronal CDK5 dysregulation also exhibit re-expression of different cell cycle markers in terminally differentiated neurons. ${ }^{17}$ Indeed, cell cycle reactivation is considered an important feature of neurological disorders. $^{18}$

In this study, we investigated the molecular mechanism of neuronal apoptosis elicited by S1P accumulation. Parallel experiments were conducted using S1P in S1P-lyasedeficient neurons or the semi-synthetic cimesP in wild-type neurons. Our results suggest that neuronal death induced by sphingoid-base phosphates is independent of mitochondria but involves calpain activation. This protease triggered the ER stress-specific caspase cascade and also CDK5-mediated cell cycle re-entry. Calpain-dependent CDK5 activation could be correlated in addition with hyperphosphorylation of tau, that forms neurofibrillary tangles in $A D$ and several other neurological disorders known as tauopathies. ${ }^{19}$ In this study, we also provide evidence of the pathophysiological impact of sphingoid-base phosphate neurotoxicity. The apoptotic pathway described in this study may, therefore, be of particular interest for the development of new strategies in the treatment of neurodegenerative disorders that are triggered by sphingoid-base phosphates generated by SK2.

\section{Results}

Cimes fails to induce apoptosis in sphingosine-kinase2deficient neurons. In a previous study, we have shown that cimesP is mainly generated by SK2. ${ }^{12}$ We have also shown that in S1P-lyase-deficient neurons S1P induces apoptosis only when generated by SK2. ${ }^{12}$ We now compared the neurotoxicity of cimes in granule cells prepared from wildtype, SK1- and SK2-deficient mice. As depicted in Figure 2 cimes reduced viability of wild-type neurons as well as of SK1-deficient cells, whereas it did not affect viability of SK2deficient neurons (Figure 2a). Accordingly, effector-caspase activation was measured only in wild-type and SK1-deficient neurons (Figure 2b). Similarly, DNA fragmentation occurred only in these two cell types (Figure 2c) whereas SK2deficient neurons were unaffected (Figure 2). Therefore, the reader should keep in mind that throughout this study cells were incubated with cimes but the biologically active compound was, in fact, SK2-generated phosphate (cimesP).

Cimes induces intracellular calcium signaling without affecting mitochondrial function. Extracellular application of cimes or S1P leads to an increase in the intracellular calcium concentration, ${ }^{15}$ most likely due to release of calcium from the ER. ${ }^{8}$ Prolonged incubation of cerebellar neurons with cimes, which leads to the intracellular accumulation of the metabolically stable cimesP, induced long-lasting and persistent increases in the resting intracellular calcium $\left([\mathrm{Ca}]_{\mathrm{i}}\right)$ which amounted up to $900 \mathrm{nM}$ after $16 \mathrm{~h}$ of incubation (Figure 3a). As expected, incubation of neurons (up to $24 \mathrm{~h}$ ) with the short-lived S1P had no effect on the resting $[\mathrm{Ca}]_{\mathrm{i}}$ (Figure 3a). Yet, brief applications of S1P induced a transient increase of $[\mathrm{Ca}]_{\mathrm{i}}$ (Figure $3 \mathrm{~b}$ ), a finding that is consistent with previous reports on different cell types. ${ }^{9,15}$ To assure that neurons were capable to produce calcium signals cells were challenged with high extracellular potassium. As shown in Figure $3 \mathrm{~b},>95 \%$ of the cells responded with robust transient increases in $[\mathrm{Ca}]_{i}$ upon $\mathrm{KCl}$-induced depolarization.

Disturbance of calcium homeostasis often affects mitochondrial functions. ${ }^{20}$ We therefore investigated whether mitochondria are involved in cimes-induced neuronal cell death by studying cytochrome $c$ release into cytosol. However, cytochrome $c$ could not be detected in the cytosolic fraction of cells treated with cimes $(10 \mu \mathrm{M})$ indicating integrity of mitochondria (Figure 3c). To verify our findings we used neurons from S1P-lyase-deficient mice incubated with S1P $(10 \mu \mathrm{M})$ and compared them to wild-type neurons treated alike. As illustrated in Figure $3 d$, no cytochrome $c$ could be detected in the cytosolic fraction of S1P-lyase-deficient mice in the presence of S1P.

Furthermore, mitochondrial integrity was analyzed in the absence or presence of cimes using the fluorescent cationic dye JC-1. These measurements revealed that cimes does not reduce the number of intact mitochondria in terminally differentiated cerebellar neurons (Figure $3 e$ ). As positive control neurons were incubated in the presence of carbonylcyanide m-chlorophenyl hydrazone (CCCP), which abolishes mitochondrial membrane potential (Figure 3e).

Mitochondria independent apoptosis is promoted by caspase-9 and caspase-12. As shown in Figure $2 b$ caspase activity is considerably increased in cells incubated with cimes. We therefore examined which of the initiator-caspases was responsible for activation of effectorcaspase-3. As depicted in Figure 4a caspase-8 was not activated in the presence of the sphingoid-base phosphate. Instead of that caspase-9 was activated (Figure 4b), which is usually linked to the mitochondrial death pathway that we just excluded (see above). To confirm this unexpected result we used Z-LEHD-FMK, a specific caspase-9 inhibitor, which almost completely prevented cimes-induced effectorcaspase-3 activation (Figure 4c). However, neuronal viability 

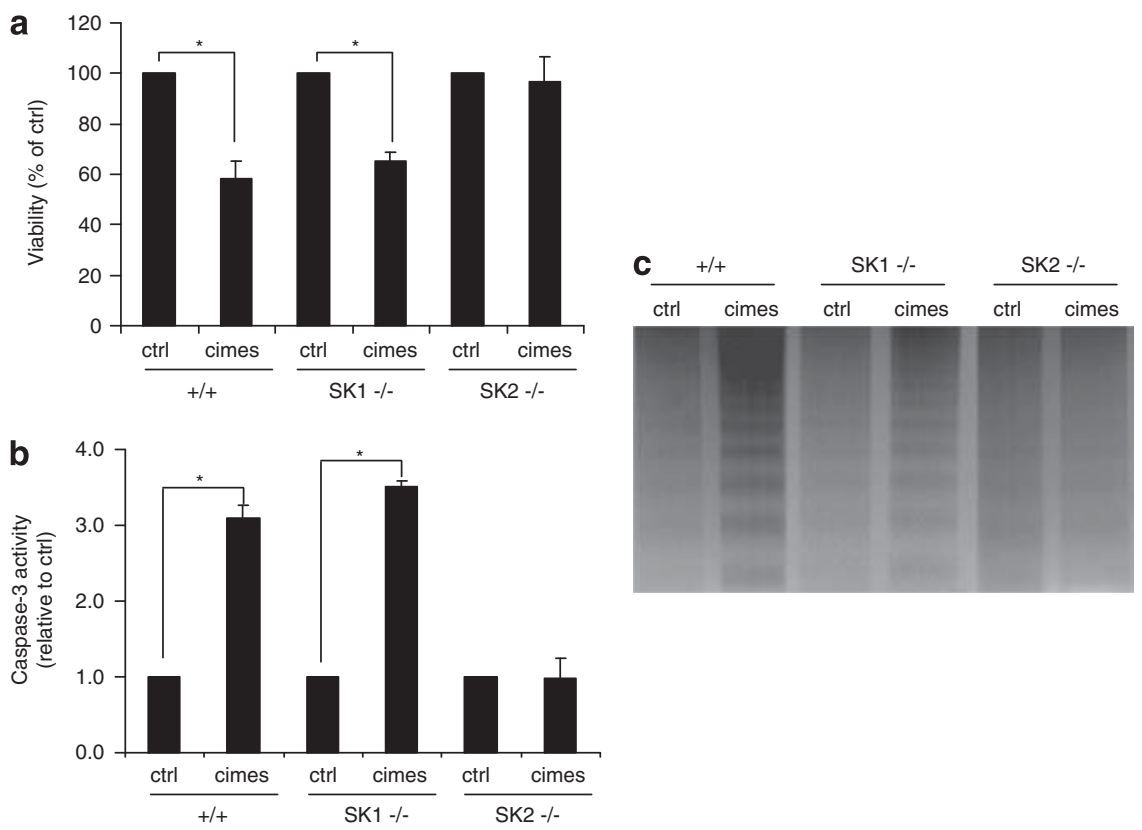

Figure 2 Cimes does not induce apoptosis in SK2-deficient neurons. Cerebellar neurons from wild-type $(+/+)$, SK1-deficient (SK1-/-) and SK2-deficient (SK2-/-) mice were incubated with vehicle (ctrl, control) or $10 \mu \mathrm{M}$ cimes. After $24 \mathrm{~h}$ cell viability (a), caspase-3 activity (b) and DNA fragmentation (c) were determined. Viability and caspase-3 activity are expressed relative to the controls of the respective genotype and represent mean values \pm S.D. $(n=3)$. ${ }^{*}$ Different $(P<0.05)$ from controls of the respective genotype

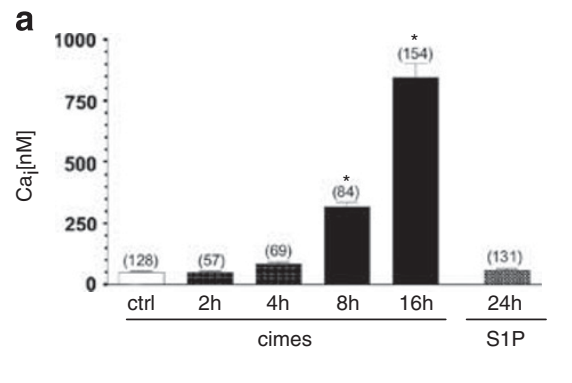

C cytosolic mitochondrial
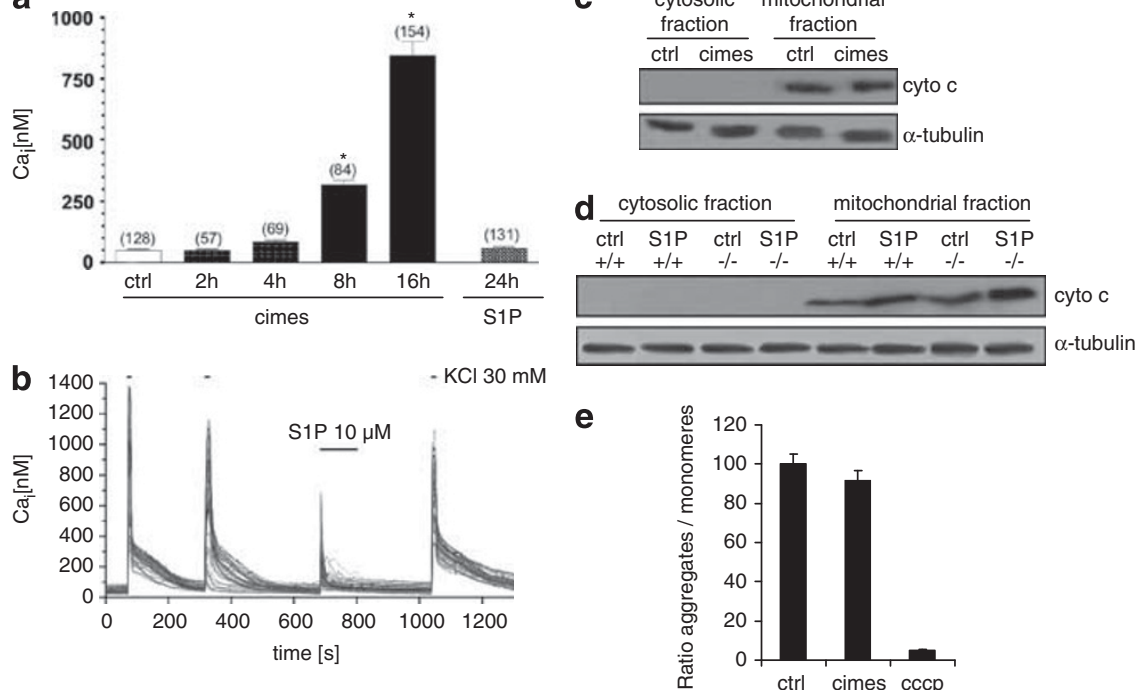

Figure 3 Prolonged application of cimes induces gradual increases in intracellular calcium concentration $\left(\left[\mathrm{Ca}^{2+}\right]_{i}\right)$ without affecting mitochondrial function. (a) Neurons were incubated for the indicated times with cimes or S1P $(10 \mu \mathrm{M}$ each) and calcium measurements were performed as described in Materials and Methods. Values are mean \pm S.E.M., number of cells examined are given in brackets. (b) Time course of $\left[\mathrm{Ca}^{2+}\right]_{i}$ in individual cells following application of $\mathrm{KCl}$ or $\mathrm{S} 1 \mathrm{P}$ as indicated. The horizontal bars illustrate the application duration $(30 \mathrm{~s}$ for $\mathrm{KCl}, 120 \mathrm{~s}$ for $\mathrm{S} 1 \mathrm{P})$. ${ }^{*}$ Different from untreated controls $(P<0.05)$. (c and d) Western blot analysis of cytochrome $c$. Cerebellar neurons from wild-type $(+/+)$ or S1P-lyase-deficient $(-I-)$ mice were treated for $24 \mathrm{~h}$ with vehicle (ctrl, control), cimes or S1P (10 $\mu \mathrm{M}$ each). Cell lysates were probed for cytochrome c content. (e) Neurons were incubated for $24 \mathrm{~h}$ in the absence or presence of cimes $(10 \mu \mathrm{M})$. Then JC-1 was added and as the ratio of J-aggregates to JC-1 monomers was determined. As a positive control, neurons were incubated with $100 \mu \mathrm{mol} / \mathrm{ICCCP}$ for $45 \mathrm{~min}$ before JC-1 staining. For quantification control cells were used as reference and set to $100 \%$

(Figure 4e) and DNA integrity (Figure 4d) were only partially improved by this inhibitor. As caspase- 9 was activated independently of cytochrome $c$ release, we considered an alternative activation pathway, namely, the ER stress-specific apoptotic pathway involving particularly caspase-12. ${ }^{21,22}$ Consistent with this pathway, we found an 

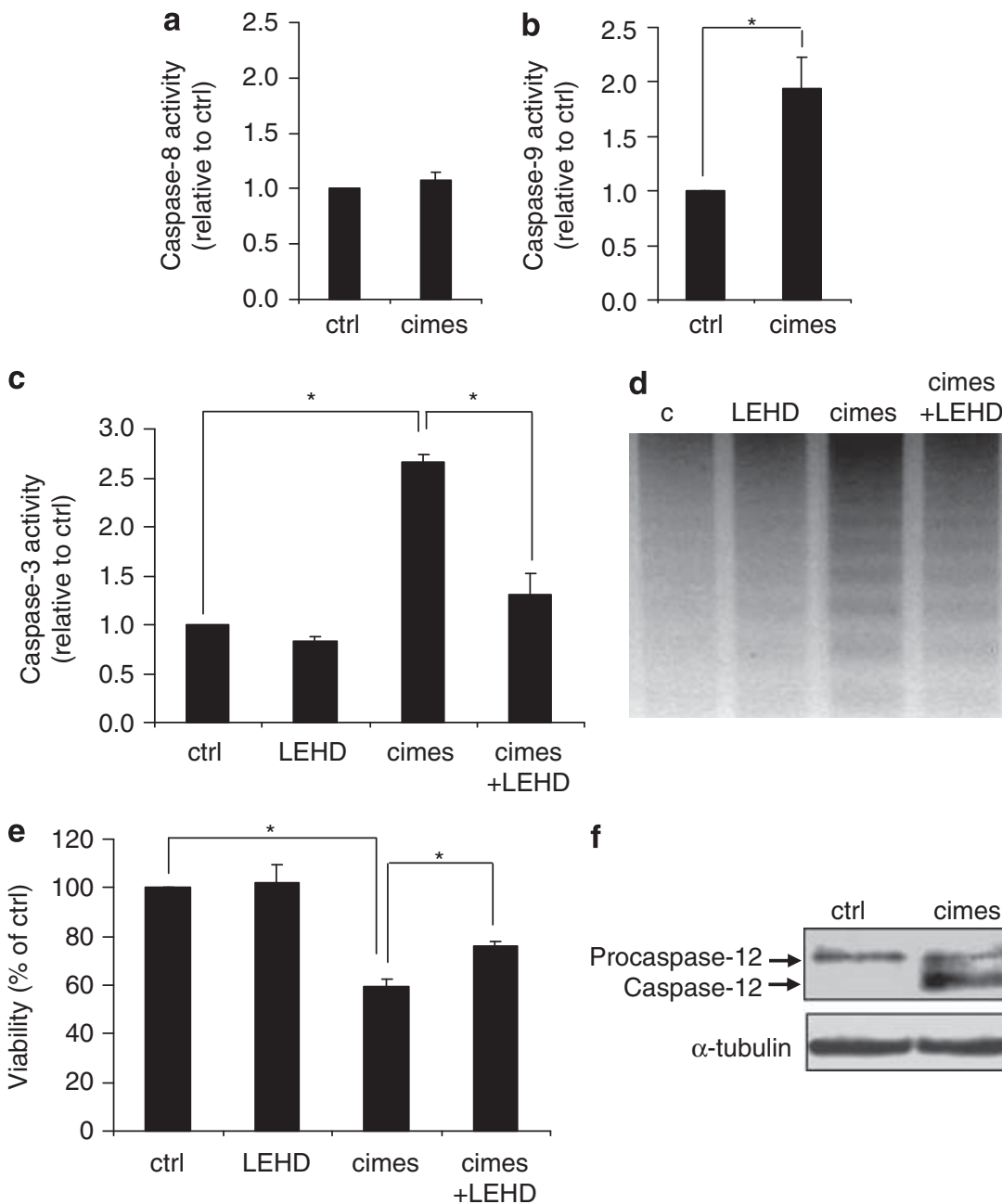

f

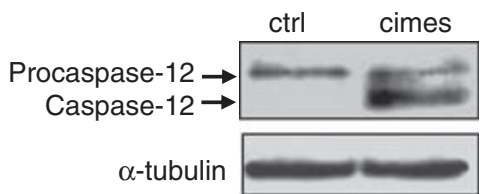

Figure 4 Mitochondria independent apoptosis is promoted by caspase-9 and caspase-12. Cerebellar neurons were treated for $24 \mathrm{~h}$ with vehicle (ctrl, control), cimes $(10 \mu \mathrm{M})$, the caspase-9 inhibitor Z-LEHD-FMK (LEHD, $100 \mu \mathrm{M})$ or a combination of cimes and LEHD (cimes + LEHD) as indicated. Then activity-assays of caspase-8 (a), caspase-9 (b), and caspase-3 (c), or DNA analysis (d) and viability assays (e) were performed. Data represent mean values \pm S.D. $(n=3)$. ${ }^{*} P<0.05$. Activation of caspase-12 (f) was analyzed by western blotting

activation of caspase-12 in the presence of cimesP (Figure 4f) that, in turn, activates caspase-9 in a cytochrome $c$ independent manner.

Calpain mediates cimes-induced neurotoxicity. As shown in Figure 4 reduced cell viability and apoptotic DNA cleavage persisted even after almost complete abrogation of caspase activity. Based on the fact that sphingoid-base phosphates induce calcium release from the $\mathrm{ER}^{8}$ and calpain was shown to induce caspase- 9 independently of cytochrome $c$ release, ${ }^{23}$ we explored a possible involvement of this calcium-dependent regulatory protease in cimes-induced neurotoxicity. On the one hand, western blot analysis revealed a strong upregulation of calpain expression in neurons incubated with cimes (Figure 5a). On the other hand, MDL28170, an effective pharmacological inhibitor shown to specifically suppress calpain activity, ${ }^{24}$ completely rescued neurons from cimes-induced toxicity (Figure 5b). Accordingly, pre-incubation of cells with MDL28170 $(10 \mu \mathrm{M})$ largely prevented caspase activation and DNA degradation
(Figures $5 c$ and d). Interestingly, inhibition of calpain also prevented morphological changes induced by cimes (Figure 5e). As it becomes clear from Figure 5e, neurons treated with cimes $(24 \mathrm{~h}, 10 \mu \mathrm{M})$ showed the typical changes in morphology, specifically cell-aggregates connected by radially running neurites, whereas MDL-treated neurons retained the morphology of control cells.

\section{Reactivation of cell cycle depends on calpain and CDK5/} p25. We have shown previously that cimes as well as S1Pinduced neuronal apoptosis involves an inappropriate cell cycle reactivation. ${ }^{12,13}$ The fully protective effect of MDL encouraged us to investigate the role of calpain for cell cycle reactivation in these post-mitotic neurons. First, we examined whether depletion of cytosolic calcium affects cimes-induced expression of cyclin D1. As depicted in Figure $6 \mathrm{a}$, the cell permeable calcium-chelator Bapta-AM completely abrogated cyclin D1 expression induced by cimes. We observed the same result after incubation of the cells with the calpain inhibitor MDL (Figure 6b), once more 
a

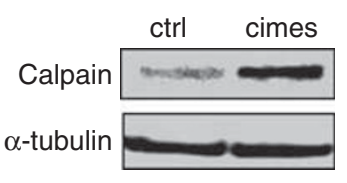

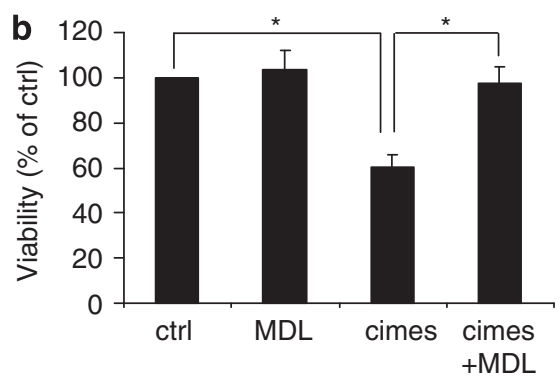

C

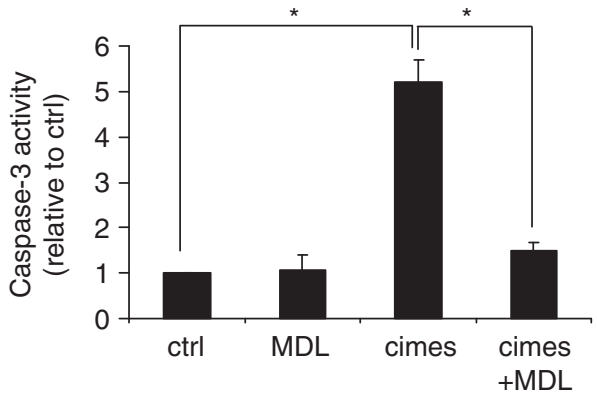

d ctrl MDL cimes +MDL e

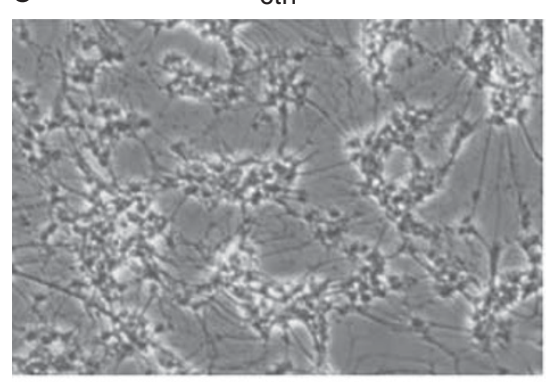

MDL

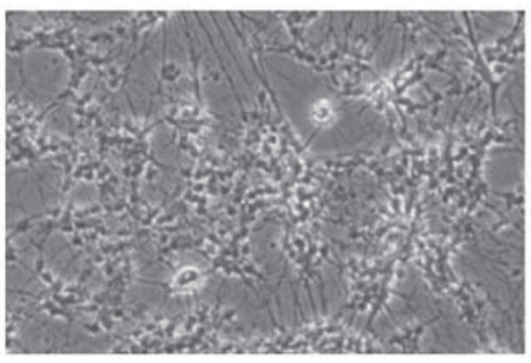

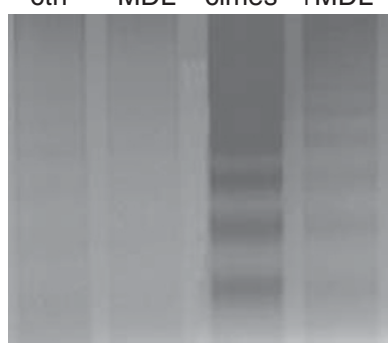

cimes

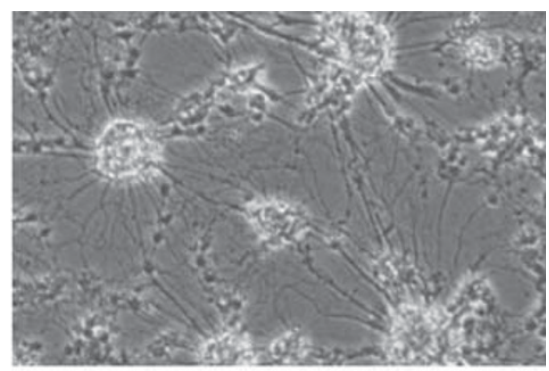

cimes + MDL

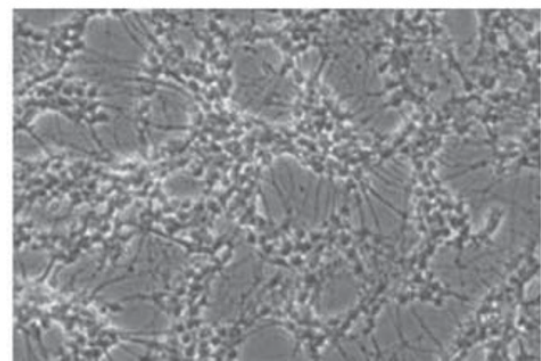

Figure 5 Calpain mediates cimes neurotoxicity. Cerebellar neurons were pre-incubated for $1 \mathrm{~h}$ with the calpain inhibitor MDL 28170 (MDL, $10 \mu \mathrm{M})$ as indicated. Then vehicle (ctrl, control) or cimes $(10 \mu \mathrm{M})$ were added for $24 \mathrm{~h}$. Expression of calpain (a) was studied in cell lysates by western blot analysis using anti-calpain antibody. Cell viability (b), caspase-3 activity (c) and DNA fragmentation (d) were determined as described in Materials and Methods. Data represent mean values \pm S.D. $(n=6)$. ${ }^{\star} P<0.05$. Morphological changes $(\mathrm{e})$ were analyzed with reverse-phase microscopy $(\times 100)$

suggesting the involvement of calcium-dependent factors in the observed neurotoxic effects of sphingoid-base phosphates. We therefore aimed to identify downstream targets of calpain, which could promote cell cycle re-entry. As shown in Figures $6 \mathrm{c}$ and $\mathrm{e}$, MDL substantially abrogates cimesinduced upregulation of CDK5 and p25, suggesting their involvement in signaling downstream of calpain. Similar results were obtained with S1P in S1P-lyase-deficient neurons (Figure 6d). Furthermore, MDL completely abolished cimesinduced phosphorylation and thus inactivation of the inhibitory cell cycle regulator $\mathrm{Rb}$ (retinoblastoma protein) (Figure 6f). These results indicate that reactivation of neuronal cell cycle involves cytosolic calcium and a calpain-dependent formation of p25 accompanied by an upregulation of CDK5 and phosphorylation of $\mathrm{Rb}$.

\section{Calpain mediates cimes-induced tau hyperphosphorylation.} Hyperphosphorylation of the microtubule-associated protein tau is a characteristic feature of neurodegenerative disorders (tauopathies) including Alzheimer's disease. ${ }^{25}$ We therefore 


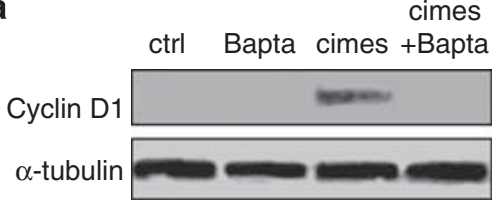

C
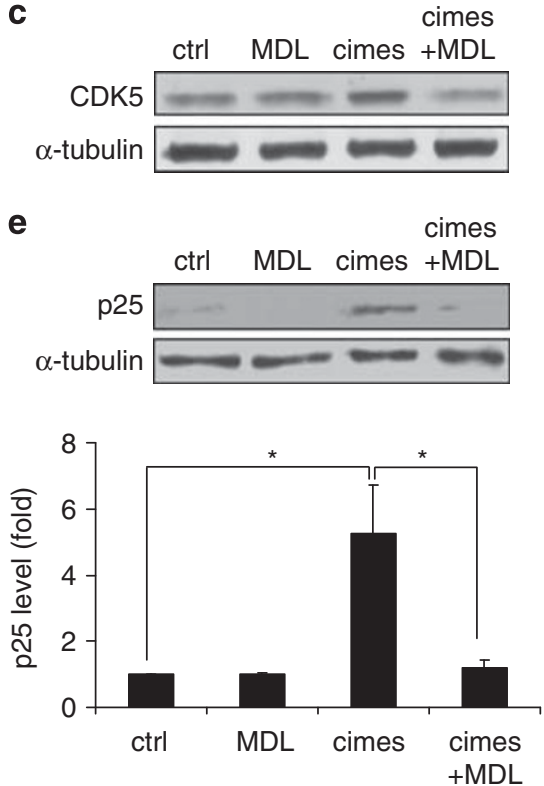

cimes

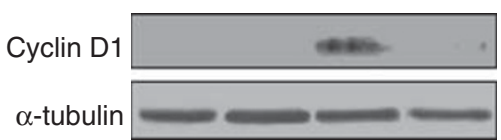

d

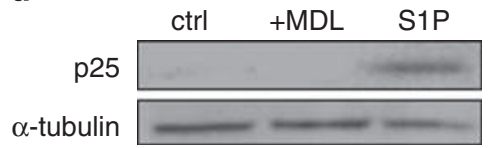

$\mathbf{f}$
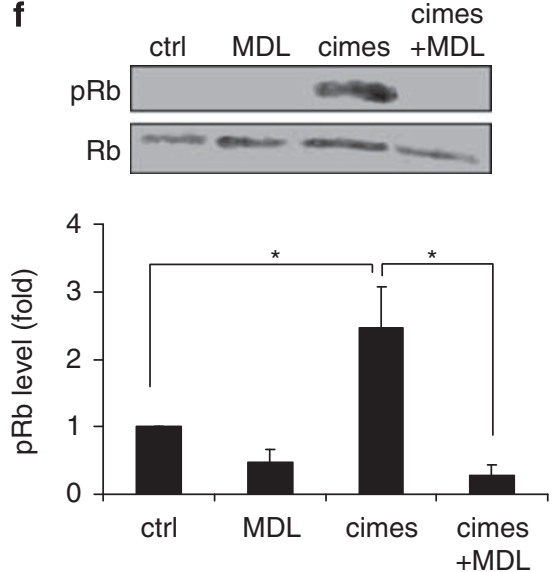

Figure 6 Reactivation of the cell cycle by sphingoid phosphates depends on calpain and CDK5/p25. Cerebellar neurons from wild-type (a-c, e and f) and S1P-lyasedeficient (d) mice were pre-incubated for 30 min with Bapta-AM $(10 \mu \mathrm{M})$ or $\mathrm{MDL}(10 \mu \mathrm{M})$ as indicated. Then vehicle (ctrl, control), cimes, or S1P (10 $\mu \mathrm{M}$ each) were added. After $24 \mathrm{~h}$ cells were lysed and expression of cyclin D1 (a and b), CDK5 (c), p25 (d and e), or pRb (f) was analyzed by western blotting. Quantitative data (mean values \pm S.D., $n=3$ ) were evaluated by densitometry. ${ }^{*} P<0.05$

investigated whether sphingoid-base phosphates promote excessive phosphorylation of tau. Indeed, incubation of wildtype and S1P-lyase-deficient neurons with cimes and S1P, respectively, results in an enhanced tau phosphorylation at the PHF-1 site (S396 and S404) (Figure 7a). Further studies with cimes revealed additional phosphorylation of tau at the 12E8 site (S262 and S214) (Figure 7b). PHF-1 recognizes phosphorylated motifs in the flanking region of the internal repeat domain while $12 \mathrm{E} 8$ binds to phosphorylated serine residues of the KXGS motifs within the repeat domain. In both cases the calpain inhibitor MDL reversed cimes-induced hyperphosphorylation of tau, whereas MDL alone did not affect tau phosphorylation.

Pathophysiological impact of S1P. To investigate the physiological relevance of accumulating sphingoid-base phosphates, we compared sagittal sections through the cerebellar vermal region of S1P-lyase-deficient and wild-type mice. As shown in Figure 8, S1P-lyase immunoreactivity is mainly and regularly present in Purkinje cells as well as in (Bergmann) glial cell processes and some scattered interneurons (Figures $8 \mathrm{a}$ and $\mathrm{b}$ ). Note that in corresponding regions from cerebella of S1P-lyase-deficient mice no immunoreactivity was detectable (Figures $8 \mathrm{c}$ and $\mathrm{d}$ ). Analysis of the cerebellar cortex of wild-type (Figure $8 \mathrm{e}$ ) and S1P-lyase-deficient mice (Figure $8 \mathrm{f}$ ) reveals the presence of scattered small groups of degenerating Purkinje cells only in S1P-lyase-deficient mice.

\section{Discussion}

In a recent study, we have shown that in terminally differentiated neurons cimes is mainly phosphorylated by SK2 (90\%) and only a poor substrate for SK $1 .{ }^{12}$ We now demonstrate that SK2 activity is indispensable for the apoptotic effect of cimes. Thus, our results clearly show that cimes induces apoptosis in wild-type and SK1-deficient neurons whereas it fails to induce apoptosis in SK2-deficient neurons. It is well known that the two isoenzymes catalyzing sphingosine phosphorylation have opposite effects on cellular growth and apoptosis. While SK1 generates S1P, which promotes cell growth and rescues cells from ceramideinduced apoptosis, overexpression of SK2 suppresses growth and enhances cell death. ${ }^{7}$ Interestingly, structural analogs of sphingosine, including FTY720, ${ }^{26}$ FTY720 analogs ${ }^{27}$ and cimes $^{12}$ are mainly phosphorylated by the less substratespecific SK2. ${ }^{6}$ It was shown that some of them induced apoptosis. $^{12,27}$

Despite some contradictory findings on localization of SK isoenzymes, it is generally accepted that SK1 is predominantly cytosolic and translocated to the plasma membrane upon activation ${ }^{7,28}$ whereas SK2 is associated with internal 
b
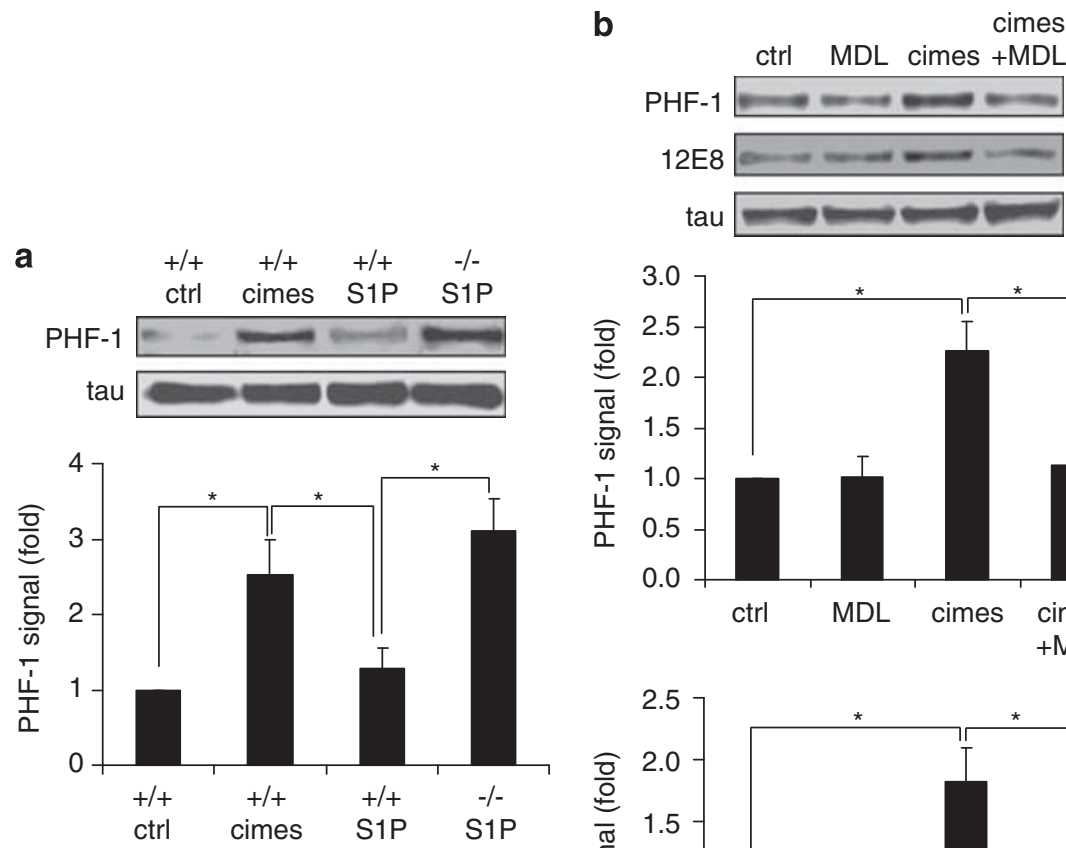

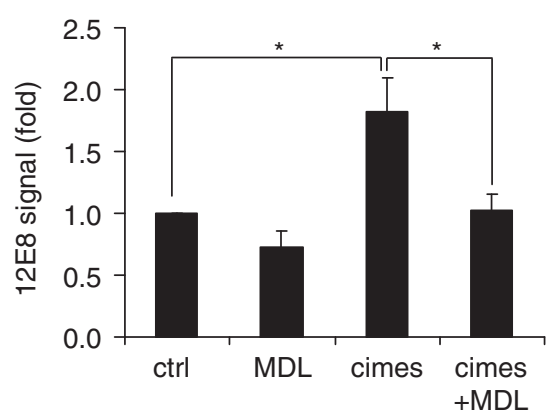

Figure 7 Calpain mediates cimes-induced tau hyperphosphorylation. (a) Cerebellar neurons from wild-type $(+I+)$ and S1P-lyase-deficient $(-I-)$ mice were incubated for $24 \mathrm{~h}$ with vehicle (ctrl, control), cimes or S1P $(10 \mu \mathrm{M}$ each). (b) Alternatively, wild-type cerebellar neurons were pre-incubated for $1 \mathrm{~h}$ with MDL 28170 where indicated. Then vehicle (ctrl, control) or cimes $(10 \mu \mathrm{M})$ were added for $24 \mathrm{~h}$ as indicated. Shown are representative western blots obtained with the specific phospho-tau antibodies PHF-1 (Ser-396/404) and 12E8 (pS262/356) recognizing pathological phosphoepitopes of tau. The total amount of tau was visualized using the pan-tau antibody K9JA. Quantitative data (mean values \pm S.D., $n=4$ ) were evaluated by densitometry and are given relative to the respective untreated controls (ctrl). ${ }^{*} P<0.05$

membranes, predominantly the ER. ${ }^{20,27}$ Interestingly, SK1 also promoted apoptosis when targeted to the $\mathrm{ER}^{20}$ indicating that ER localization rather than the enzyme by itself is essential for the apoptotic effect. Using fluorescent derivatives, it has been shown that sphingoid-base phosphate analogs generated by SK2 accumulate mainly in ER membranes. ${ }^{27}$ In light of these results and in agreement with an ER localization of SK2, it appears quite likely that cimes phosphorylated by SK2 also accumulates in ER membranes. Moreover, we could show in this study that cimes downstream signaling is promoted by ER-specific proteases, including calpain and caspase-12. In addition, we could exclude involvement of mitochondria in cimes-induced neuronal apoptosis. This was an unexpected finding given the clear activation of caspase- 9 , which has been shown to depend on cytochrome $c$ release.$^{29}$ Also, mitochondria permeabilization was proposed as part of the sphingoid-base phosphateinduced apoptotic pathway in immune cells. ${ }^{27}$ Cimes failed, however, to induce cytochrome $c$ release and caspase- 8 activation indicating that the sphingoid-base phosphate pro-apoptotic pathway in neurons is different.

The observation that caspase- 9 was activated independently of cytochrome $c$ release, prompted us to look for ER-dependent factors that might be responsible for sphingoid-base phosphate-induced activation of procaspase-9.
In agreement with previous findings, ${ }^{22}$ our results indicate that cimes activates caspase-12, which then specifically cleaves procaspase- 9 in a mitochondria-independent manner. Cleavage and hence activation of caspase-12 has been suggested to be catalyzed by calpain. ${ }^{23}$ This cytosolic protease is activated by increased cytosolic calcium levels, which induce its translocation from the cytosol to ER membranes. As cimes promoted a persistent elevation of intracellular calcium concentration, activation of calpain appeared quite likely. Calpain activation has been described in several neuronal pathologies, many of them including CDK5 dysregulation caused by calpain catalyzed cleavage of CDK5 regulatory subunit p35. ${ }^{30}$ The resulting p25 subunit lacks the membrane anchor binding site generating a hyperactive and mislocalized CDK5/p25 complex. ${ }^{30}$ Note, that CDK5 is essential for normal brain development and function, but uncontrolled activity may lead to numerous neurodegenerative diseases. ${ }^{31}$ Neurotoxicity caused by the CDK5/p25 complex has been suggested to be associated with hyperphosphorylation of tau ${ }^{32}$ and/or reactivation of the cell cycle. ${ }^{33}$ Notably, cimes stimulates tau phosphorylation and induces cell cycle re-entry (Figure 9). Moreover, both effects are calpain and CDK5/p25 dependent. Hyperphosphorylation of tau caused by cimes strongly suggests that neurotoxicity of sphingoid-base phosphates might be related to an 

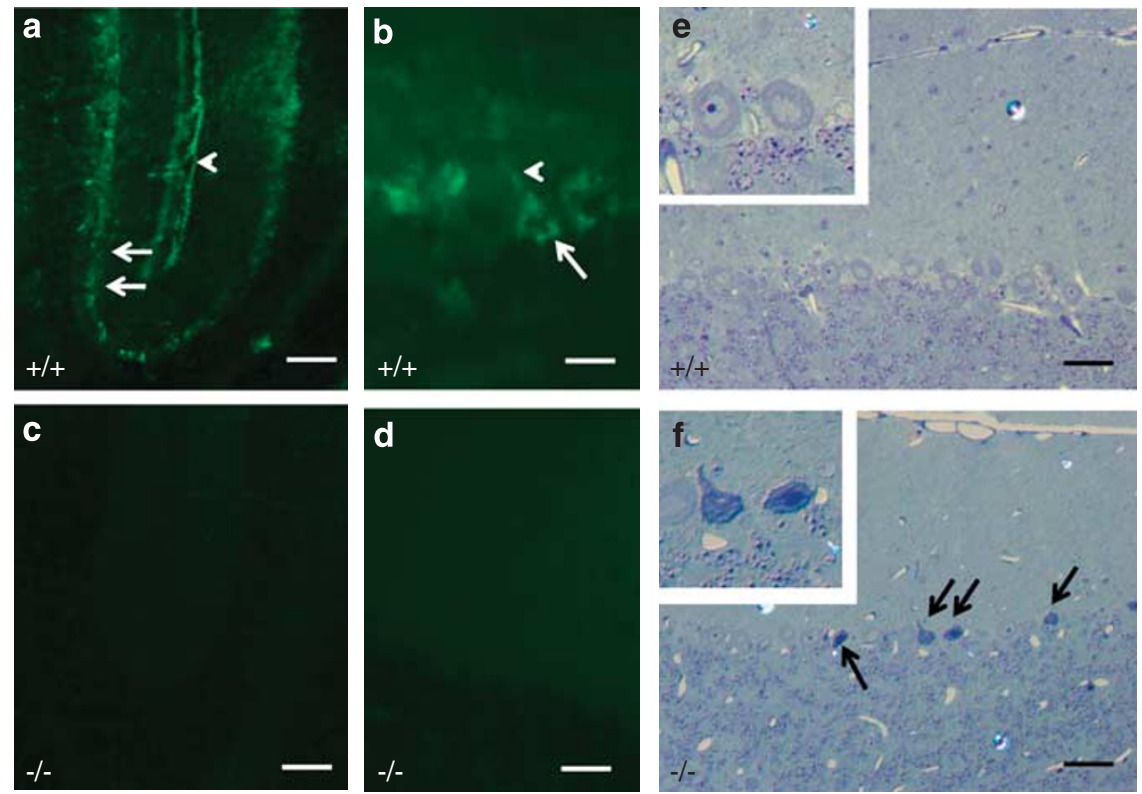

Figure 8 Correlation between S1P-lyase immunoreactivity and neuronal degeneration. Cerebella of wild-type (a and $\mathbf{b})$ and S1P-lyase-deficient (c and $\mathbf{d})$ mice were stained with an antibody against S1P-lyase. Immunoreactivity for S1P-lyase is mainly present in Purkinje cell somata (arrows in a and $\mathbf{b}$ ) and proximal dendrites (arrowhead in $\mathbf{b}$ ) as well as in the perivascular and superficial glial limiting membrane (arrowhead in a). Sections of corresponding regions from knockout mice cerebella (c and d) are devoid of S1P-lyase immunoreactivity. Sagittal sections through the cerebellar vermal region of adult wild-type $(+/+, \mathbf{e})$ and S1P-lyase-deficient $(-/-$, f) mice were stained with toluidine blue and pyronin $(\mathbf{g})$. Arrows in Figure $8 \mathrm{f}$ indicate scattered groups of degenerating Purkinje neurons in the cerebellar cortex. The insert in Figure $8 f$ shows two degenerating neurons at higher magnification, featuring darkened cytoplasm, irregular shrunken contours and in one case nuclear pyknosis. Bars correspond to $300 \mu \mathrm{m}(\mathbf{a}$ and $\mathbf{c}), 30 \mu \mathrm{m}$ (b and $\mathbf{d})$, and $50 \mu \mathrm{m}$ (e and f)
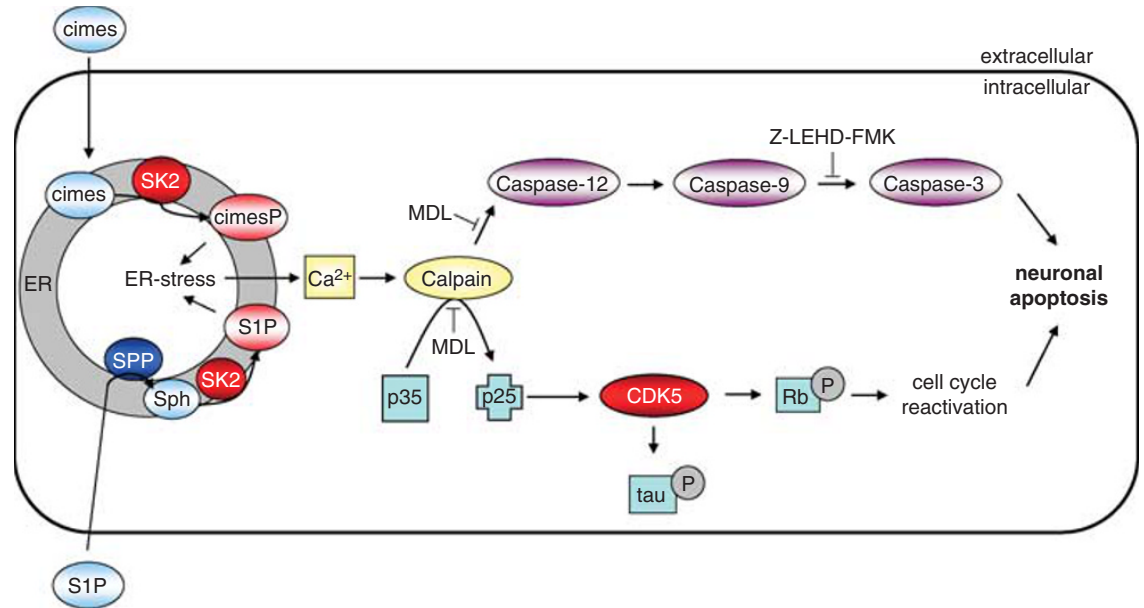

Figure 9 Proposed signaling cascade of sphingoid-base phosphate-induced neurotoxicity. Calpain is the central signaling molecule and mediates sphingoid-base phosphate-induced neuronal apoptosis by activation of ER stress-specific caspase cascade and initiation of cell cycle reactivation. In addition, calpain/CDK5-dependent tau hyperphosphorylation is induced. The metabolic fate of exogenous cimes and S1P in wild-type and S1P-lyase-deficient mice, respectively, was described previously. ${ }^{2}$ CDK5, cyclin-dependent kinase5; cimes, cis-4-methylsphingosine; cimesP, cis-4-methylsphingosine-phosphate; ER, endoplasmic reticulum; Rb, retinoblastoma protein; SK2; sphingosine-kinase2; Sph, sphingosine; SPP, sphingosine-phosphate phosphatase

abnormal tau aggregation. Interestingly, tau hyperphosphorylation was also reported in fetal tissue and in mitotic cells indicating that mitotic signals might be able to cause hyperphosphorylation of tau and hence apoptotic death in differentiated neurons. ${ }^{34}$ The mitogenic potential of cimes ${ }^{15}$ argues in favor of this hypothesis.

Collectively, our data indicate that sphingoid-base phosphates cause neuronal death by a calpain-mediated mechanism involving CDK5/p25 and the ER stress-specific caspase cascade (Figure 9).

Intriguingly, S1P-dependent neurotoxicity described in the present study shows similarity to that of the amyloid $\beta$-peptide in Alzheimer's disease. Thus, amyloid $\beta$-peptide neurotoxicity also involves procaspase- 12 activation by disruption of ER calcium homeostasis but not by membrane- or mitochondriatargeted apoptotic signals. ${ }^{21}$ Furthermore, amyloid $\beta$-peptide 
induces an aberrant reactivation of cell cycle events and activation of CDK5. ${ }^{35}$ Notably, calpain emerged as a central player in the pathogenesis of neurological disease ${ }^{16}$ thus suggesting a pathophysiological relevance of our results. Accordingly, an impaired metabolism of glycosphingolipids, which are highly abundant in the central nervous system, might be linked via S1P, their common catabolic intermediate, to neuronal death. Neuroanatomical studies document for the first time that indeed neurons with abundant S1P-lyase expression are those, which degenerate first in S1P-lyasedeficient mice. This finding suggests that S1P might be the missing link connecting impaired lipid metabolism and neurological disorders.

\section{Materials and Methods \\ Cell culture. Granule cells from cerebella of 6 days old wild-type, S1P-lyase (sgp/1) -/-, sphingosine-kinase1 (sphk1) -/- and sphingosine-kinase2 -/- mice were used. sgpl1 $+1-$ or sgp/1 - / - pups were inbred in a Swiss Webster genetic background. Heterozygous sgpl $1+I-$ non-inbred mouse was generated from gene trapped ES cells (OST 58278) by Lexicon Inc. (The Woodlands, TX, USA) on a fee basis. ${ }^{36}$ To generate the sphk1 and sphk2 null mice, a genomic DNA fragment was cloned containing the sphk1 and sphk2 gene, respectively, from a $129 /$ sv strain library inbred in a C57/BL6 background ${ }^{26,37}$ For all transgenic mice, heterozygous matings were set up to generate homozygous mutant mice. Mice were bred in the animal house of the University in Bonn (Germany). \\ The neuronal cells were cultured as described before. ${ }^{14}$ Briefly, cells were isolated by mild trypsinization $(0.05 \% \mathrm{w} / \mathrm{v})$ and dissociated by repeated passage through a constricted Pasteur pipette in a DNase solution $(0.1 \% \mathrm{w} / \mathrm{v})$. The cells were then suspended in Dulbecco's modified Eagle medium (containing 10\% heat-inactivated horse serum, penicillin $100 \mathrm{U} / \mathrm{l}$, and streptomycin $100 \mathrm{mg} / \mathrm{l}$ ) and plated on to poly-L-lysine-coated $8 \mathrm{~cm}^{2}$ Petri dishes $\left(6 \times 10^{6} \mathrm{cells} / \mathrm{dish}\right)$. At day 5 in culture primary neurons were treated with $10 \mu \mathrm{M}$ cimes (synthesized as described $^{38}$ ), S1P, or the caspase-9 inhibitor Z-LEHD-FMK (R\&D Systems, Wiesbaden, Germany) for the indicated times. In some experiments pre-incubations with the calpain inhibitor MDL28170 (Sigma, Taufkirchen, Germany) or the cell permeable calcium-chelator Bapta-AM (Invitrogen, Karlsruhe, Germany) were performed as indicated.}

Calcium imaging. Neurons were loaded with the $\mathrm{Ca}^{2+}$ sensitive dye Fura-2AM ( $3 \mu \mathrm{M}$, Molecular Probes Europe BV, Leiden, The Netherlands) at $37^{\circ} \mathrm{C}$ in bicarbonate-buffered saline solution containing (mM): $156 \mathrm{NaCl}, 2 \mathrm{KCl}, 2 \mathrm{CaCl}_{2}$, $1 \mathrm{MgCl}_{2}, 26 \mathrm{NaHCO}_{3}, 1.25 \mathrm{NaH}_{2} \mathrm{PO}_{4}$ and 10 glucose, gassed with $5 \% \mathrm{CO}_{2}, \mathrm{pH} 7.3$. Background corrected fluorescence was taken with a slow-scan CCD camera system with fast monochromator (TILL Photonics, Grafelfing, Germany) coupled on an Axiovert 100 microscope equipped with an Neofluar objective $(\times 10$, Zeiss, Oberkochen, Germany). Fura-2 was excited at 357 and $380 \mathrm{~nm}$ wavelengths, and fluorescence was collected between 500 and $540 \mathrm{~nm}$ at a frequency of $0.5 \mathrm{~Hz}$. The change in $\left[\mathrm{Ca}^{2+}\right]_{i}$ is presented as the change in the fluorescence ratio obtained at the two excitation wavelengths (F357/F380). This experimental set-up allowed for the two-dimensional representation of $\mathrm{Ca}^{2+}$ signals in all cells simultaneously. Average values of fluorescence intensity from somatic regions were chosen for quantification ( $\sim 50-80$ pixels) and analyzed off-line with routines written in Igor Pro software (Wavemetrics, Eugene, OR, USA). A neuron was included in the analysis if the peak of the response from a $30 \mathrm{~s}$ reference application of $30 \mathrm{mM} \mathrm{KCl}$ was larger than threshold, defined as six S.D. of the baseline noise. ${ }^{39}$ The same baseline S.D. criterion was used to count cells responsive to other substances and to calculate the average peak amplitudes. All recordings were carried out at room temperature $\left(22-25^{\circ} \mathrm{C}\right)$ in Hepes-buffered saline containing $(\mathrm{mM}): 145 \mathrm{NaCl}, 2.5 \mathrm{KCl}, 2 \mathrm{CaCl}_{2}$, $1.3 \mathrm{MgCl}_{2}, 10$ Hepes and 20 glucose, $\mathrm{pH}$ 7.3. In solutions with elevated $\mathrm{KCl}$ $(20 \mathrm{mM}), \mathrm{NaCl}$ concentration was reduced by the same amount. Solutions were applied using a focal perfusion system (DAD-12, ALA Scientific Instruments, Westbury, NY, USA).

Caspase assay. Caspase assays were performed according to provider's protocol (Invitrogen). Cell pellets were re-suspended in $50 \mu$ l of cold lysis buffer and incubated in ice for $15 \mathrm{~min}$. After addition of $50 \mu \mathrm{l}$ reaction buffer, containing dithiothreitol (10 mM) and IETD-, LEHD- or DEVD-p-nitroaniline substrate $(50 \mu \mathrm{M})$, samples were incubated for $2 \mathrm{~h}$ at $37^{\circ} \mathrm{C}$ in the absence of light. Absorbance was measured at $405 \mathrm{~nm}$. Caspase activities are expressed relative to untreated wild-type controls.

Cell viability assay. For quantification of cell death in cultured cells, we employed the CellTiter-Blue Cell Viability Assay (BD Pharmingen, Heidelberg, Germany), which is based on the conversion of resazurin to the fluorescent product resorufin exclusively by metabolically active (viable) cells. Following the indicated treatment of neurons, $100 \mu \mathrm{l}$ of CellTiter-Blue reagent were added to each cell culture dish. After $1 \mathrm{~h}$ of incubation, fluorescence of resorufin was recorded in an aliquot $(100 \mu l)$ culture medium at $544_{\mathrm{Ex}} / 590_{\mathrm{Em}}$.

Genomic DNA analysis. Genomic DNA analysis was performed as described previously. ${ }^{12}$ In brief, cells were harvested in the respective medium and centrifuged $\left(2000 \times \mathrm{g}, 10 \mathrm{~min}, 4^{\circ} \mathrm{C}\right)$, thus collecting both adherent and detached cells. Cell pellets were then re-suspended in $500 \mu \mathrm{l}$ ice cold phosphatebuffered saline (PBS) and centrifuged again $\left(2000 \times \mathrm{g}, 10 \mathrm{~min}, 4^{\circ} \mathrm{C}\right)$. Genomic DNA was purified using QIAamp DNA Blood Mini Kits (Qiagen, Hilden, Germany) according to the protocol of the provider. Finally, samples were loaded onto a $1.6 \%$ agarose gel. Following electrophoresis DNA was visualized under UV light using ethidium bromide.

Mitochondrial integrity. JC-1 (Cell Technology Inc., Mountain View, CA, USA) is a common tool to assess the polarization status of mitochondrial membranes. This fluorescent dye forms so-called J-aggregates (red fluorescence) in intact negatively charged mitochondria. As soon as the mitochondrial membrane potential collapses, $\mathrm{JC}-1$ is dispersed throughout the cell in a monomeric form (green fluorescence). Thus, neurons were pretreated as indicated and incubated with JC-1 following provider's protocol. Then cells were washed and JC-1 monomers were assessed using excitation/emission wavelength of $485 / 530 \mathrm{~nm}$, while J-aggregates were measured at 560/595 nm.

In addition, cytochrome $c$ release was analyzed using the cytochrome $c$ release apoptosis assay kit from Calbiochem (Merck, Darmstadt, Germany) following provider's protocol.

Neuroanatomical studies. Mice (7 weeks of age) were killed by an overdose of chloroform and then perfused via the left ventricle with Sörensen phosphate buffer containing $1 \%$ procaine followed by a further perfusion with either $6 \%$ glutardialdehyde (for epoxy resin embedding and semi-thin sectioning) or $2 \%$ paraformaldehyde (for further vibratome sections and immunohistochemistry) in the same buffer. For epoxy resin embedding, tissues were post-fixed at least overnight, rinsed in buffer, and dissected tissue samples embedded in Epon/glycid ether after osmication following standard procedures. Sections were cut at $1 \mu \mathrm{m}$ and stained with toluidine blue/pyronin G. For immunohistochemistry, brains were rinsed in Sörensen buffer, encased in agarose and cut on a high-frequency vibratome (Leica VT 1200 S, Leica, Wetzlar, Germany). After antigen retrieval and blocking, sections were incubated with an S1P-lyase antibody (Abcam, Cambridge, UK) at a 1:100 dilution, and the binding of the primary antibody was detected by the use of a HRP-tagged secondary antibody using tyramide-FITC (NEN-Dupont) as a fluorescent substrate. Nuclear counterstaining was done with bisbenzimide (Sigma, Deisenhofen, Germany). Specimens were photographed on an Nikon 90i epifluorescence microscope equipped with a 4-channel EZ-C1 confocal laser system.

Western blotting. SDS-PAGE and western blotting were performed as described earlier. ${ }^{12}$ Cells were lysed for $10 \mathrm{~min}$ at $4^{\circ} \mathrm{C}$ in cell lysis buffer (Cell Signaling, Danvers, MA, USA) containing protease inhibitors (Invitrogen). Cell extracts were centrifuged at $10000 \times g$ for $10 \mathrm{~min}$ at room temperature to separate insoluble material, followed by determination of protein concentration using the BCA assay (Sigma-Aldrich, Taufkirchen, Germany). Proteins from each sample were mixed with loading buffer (RotiLoad, Roth, Karlsruhe, Germany), boiled for 10 min and subjected to SDS-PAGE followed by transfer to nitrocellulose membranes for $6 \mathrm{~min}$ via the iBlot (Invitrogen). Membranes were blocked for $1 \mathrm{~h}$ with $5 \%$ non-fat milk in TBS at room temperature and subsequently probed with the desired primary antibody. Blots were revealed by ECL (Amersham Biosciences, Freiburg, Germany). The following primary antibodies were used: calpain1 (15C10), cyclin D1 (A-12), CDK5 (J-3), p35 (C-19) for p25, $\alpha$-tubulin (H-300) from Santa Cruz 
Biotechnology (Heidelberg, Germany); caspase-12, pRb (Ser 807/811), Rb (4H1) from Cell Signaling; PHF-1 from P Davies (Albert Einstein College, Bronx, NY, USA), 12E8 from $P$ Seubert (Elan Pharmaceuticals, South San Francisco, CA USA) and K9JA from DAKO (Glostrup, Denmark); cytochrome $c$ from cytochrome $c$ release apoptosis assay kit. Primary antibodies were diluted in blocking solution in accordance with provider's protocol. Secondary antibodies were diluted $1: 40000$ in TBST. To confirm equal amounts of protein loaded for each sample, blots were reprobed with respective antibody ( $\mathrm{Rb}, \alpha$-tubulin). Some western blots were densitometrically evaluated using the AlphaDigiDoc gel documentation system (Bio-Rad, München, Germany). In each experiment the ratio of absorbance of the respective protein versus loading control was calculated.

Presentation of data and statistics. All experiments were repeated at least three times with consistent results in double determinations. Data are expressed as mean values \pm S.D. or S.E.M. and normalized as indicated. Statistical analysis was performed using Student's t-test. Statistical significance was tested at $95 \%(P<0.05)$ confidence level. Results presented as DNA or protein gels correspond to data obtained with at least three different cell preparations.

\section{Conflict of interest}

The authors declare no conflict of interest.

Acknowledgements. We thank Eva-Maria Mandelkow for valuable discussions on tau phosphorylation, Paul P Van Veldhoven for providing S1P. lyase-deficient mice, Richard L Proia for providing sphingosine kinase-deficient mice, Philip Hockberger for improving the English of the manuscript, Birgit Rau and Angelika Zoons for expert technical support and Tracy Klitz for her help in breeding mice. This study was supported by DFG.

\section{Author contributions}

$\mathrm{NH}$ designed, performed experiments and wrote the paper; $\mathrm{MH}$ designed and performed calcium measurements; DH performed neuroanatomical studies; DS supervised calcium measurements and contributed to writing of the paper; GvED designed experiments and wrote the paper.

1. van Echten-Deckert G, Herget T. Sphingolipid metabolism in neural cells. Biochim Biophys Acta 2006; 1758: 1978-1994.

2. Yu RK, Ariga T. The role of glycosphingolipids in neurological disorders. Mechanisms of immune action. Ann N Y Acad Sci 1998; 845: 285-306.

3. He X, Huang Y, Li B, Gong CX, Schuchman EH. Deregulation of sphingolipid metabolism in Alzheimer's disease. Neurobiol Aging 2010; 31: 398-408.

4. Hannun YA, Obeid LM. Principles of bioactive lipid signalling: lessons from sphingolipids. Nat Rev Mol Cell Biol 2008; 9: 139-150.

5. Kohama T, Olivera A, Edsall L, Nagiec MM, Dickson R, Spiegel S. Molecular cloning and functional characterization of murine sphingosine kinase. J Biol Chem 1998; 273 23722-23728.

6. Liu H, Sugiura M, Nava VE, Edsall LC, Kono K, Poulton S et al. Molecular cloning and functional characterization of a novel mammalian sphingosine kinase type 2 isoform. J Biol Chem 2000; 275: 19513-19520.

7. Hait NC, Oskeritzian CA, Paugh SW, Milstien S, Spiegel S. Sphingosine kinases, sphingosine 1-phosphate, apoptosis and diseases. Biochim Biophys Acta 2006; 1758 2016-2026.

8. Ghosh TK, Bian J, Gill DL. Sphingosine 1-phosphate generated in the endoplasmic reticulum membrane activates release of stored calcium. J Biol Chem 1994; 269: 22628-22635.

9. Meyer zu Heringdorf D, Liliom K, Schaefer M, Danneberg K, Jaggar JH, Tigyi G et al. Photolysis of intracellular caged sphingosine-1-phosphate causes $\mathrm{Ca}^{2+}$ mobilization independently of G-protein-coupled receptors. FEBS Lett 2003; 554: 443-449.

10. Harada J, Foley M, Moskowitz MA, Waeber C. Sphingosine-1-phosphate induces proliferation and morphological changes of neural progenitor cells. J Neurochem 2004; 88 1026-1039.

11. Moore AN, Kampfl AW, Zhao X, Hayes RL, Dash PK. Sphingosine-1-phosphate induces apoptosis of cultured hippocampal neurons that requires protein phosphatases and activator protein-1 complexes. Neuroscience 1999; 94: 405-415.

12. Hagen $\mathrm{N}$, Van Veldhoven PP, Proia RL, Park H, Merrill Jr AH, van Echten-Deckert G. Subcellular origin of sphingosine 1-phosphate is essential for its toxic effect in lyase-deficient neurons. J Biol Chem 2009; 284: 11346-11353.
13. Naetzker S, Hagen N, Echten-Deckert G. Activation of p38 mitogen-activated protein kinase and partial reactivation of the cell cycle by cis-4-methylsphingosine direct postmitotic neurons towards apoptosis. Genes Cells 2006; 11: 269-279.

14. van Echten-Deckert G, Zschoche A, Bar T, Schmidt RR, Raths A, Heinemann T et al. cis-4-Methylsphingosine decreases sphingolipid biosynthesis by specifically interfering with serine palmitoyltransferase activity in primary cultured neurons. J Biol Chem 1997; 272: 15825-15833.

15. van Echten-Deckert G, Schick A, Heinemann T, Schnieders B. Phosphorylated cis-4methylsphingosine mimics the mitogenic effect of sphingosine-1-phosphate in Swiss 3T3 fibroblasts. J Biol Chem 1998; 273: 23585-23589.

16. Camins A, Verdaguer E, Folch J, Pallas M. Involvement of calpain activation in neurodegenerative processes. CNS Drug Rev 2006; 12: 135-148.

17. Hernandez-Ortega K, Ferrera $P$, Arias $C$. Sequential expression of cell-cycle regulators and Alzheimer's disease-related proteins in entorhinal cortex after hippocampal excitotoxic damage. J Neurosci Res 2007; 85: 1744-1751.

18. Yang $\mathrm{Y}$, Herrup K. Cell division in the CNS: protective response or lethal event in post-mitotic neurons? Biochim Biophys Acta 2007; 1772: 457-466.

19. Gendron TF, Petrucelli L. The role of tau in neurodegeneration. Mol Neurodegener 2009; 4: 13

20. Maceyka M, Sankala H, Hait NC, Le Stunff H, Liu H, Toman R et al. SphK1 and SphK2, sphingosine kinase isoenzymes with opposing functions in sphingolipid metabolism. J Biol Chem 2005; 280: 37118-37129.

21. Nakagawa T, Zhu H, Morishima N, Li E, Xu J, Yankner BA et al. Caspase-12 mediates endoplasmic-reticulum-specific apoptosis and cytotoxicity by amyloid-beta. Nature 2000; 403: 98-103.

22. Morishima N, Nakanishi K, Takenouchi H, Shibata T, Yasuhiko Y. An endoplasmic reticulum stress-specific caspase cascade in apoptosis. Cytochrome c-independent activation of caspase-9 by caspase-12. J Biol Chem 2002; 277: 34287-34294.

23. Nakagawa $T$, Yuan J. Cross-talk between two cysteine protease families. Activation of caspase-12 by calpain in apoptosis. J Cell Biol 2000; 150: 887-894.

24. Mehdi S, Angelastro MR, Wiseman JS, Bey P. Inhibition of the proteolysis of rat erythrocyte membrane proteins by a synthetic inhibitor of calpain. Biochem Biophys Res Commun 1988; 157: 1117-1123.

25. Lee VM, Goedert M, Trojanowski JQ. Neurodegenerative tauopathies. Annu Rev Neurosci 2001; 24: 1121-1159.

26. Allende ML, Sasaki T, Kawai H, Olivera A, MiY, van Echten-Deckert G et al. Mice deficient in sphingosine kinase 1 are rendered lymphopenic by FTY720. J Biol Chem 2004; 279: 52487-52492

27. Don AS, Martinez-Lamenca C, Webb WR, Proia RL, Roberts E, Rosen H. Essentia requirement for sphingosine kinase 2 in a sphingolipid apoptosis pathway activated by FTY720 analogues. J Biol Chem 2007; 282: 15833-15842.

28. Spiegel S, Milstien S. Sphingosine-1-phosphate: an enigmatic signalling lipid. Nat Rev Mol Cell Biol 2003; 4: 397-407.

29. Li P, Nijhawan D, Budihardjo I, Srinivasula SM, Ahmad M, Alnemri ES et al. Cytochrome c and dATP-dependent formation of Apaf-1/caspase- 9 complex initiates an apoptotic protease cascade. Cell 1997; 91: 479-489.

30. Patrick GN, Zukerberg L, Nikolic M, de la Monte S, Dikkes P, Tsai LH. Conversion of p35 to p25 deregulates Cdk5 activity and promotes neurodegeneration. Nature 1999; 402: 615-622.

31. Dhavan R, Tsai LH. A decade of CDK5. Nat Rev Mol Cell Biol 2001: 2: 749-759.

32. Lee MS, Tsai LH. Cdk5: one of the links between senile plaques and neurofibrillary tangles? J Alzheimers Dis 2003; 5: 127-137.

33. Lopes JP, Oliveira CR, Agostinho P. Cdk5 acts as a mediator of neuronal cell cycle re-entry triggered by amyloid-beta and prion peptides. Cell Cycle 2009; 8: 97-104.

34. Mandelkow EM, Mandelkow E. Tau in Alzheimer's disease. Trends Cell Biol 1998; 8 : $425-427$.

35. Lopes JP, Oliveira CR, Agostinho P. Neurodegeneration in an Abeta-induced model of Alzheimer's disease: the role of Cdk5. Aging Cell 2010; 9: 64-77.

36. VanVeldhoven PP. Sphingosine 1-phosphate lyase deficient mice. Chem Phys Lipids 2005; 136: 164-165.

37. Mizugishi K, Yamashita T, Olivera A, Miller GF, Spiegel S, Proia RL. Essential role for sphingosine kinases in neural and vascular development. Mol Cell Biol 2005; 25: 11113-11121.

38. Bar T, Kratzer B, Wild R, Sandhoff K, Schmidt RR. Synthesis of methyl-branched sphingosines. Liebigs Annalen Der Chemie 1993: 419-426.

39. Titz S, Hans M, Kelsch W, Lewen A, Swandulla D, Misgeld U. Hyperpolarizing inhibition develops without trophic support by GABA in cultured rat midbrain neurons. J Physiol 2003; 550(Part 3): 719-730.

This work is licensed under the Creative Commons Attribution-NonCommercial-No Derivative Works 3.0 Unported License. To view a copy of this license, visit http:// creativecommons.org/licenses/by-nc-nd/3.0 